\title{
The prognostic value of NRF2 in solid tumor patients: a meta- analysis
}

\author{
Lingling Wang ${ }^{1, *}$, Chunze Zhang ${ }^{2, *}$, Litao Qin ${ }^{3, *}$, Jingyue $\mathrm{Xu}^{4, *},{ }^{4}$ Xiaobo Li ${ }^{1}$, Wenhong \\ Wang $^{2}$, Lingqin Kong ${ }^{5}$, Taizhen Zhou ${ }^{6}$ and Xichuan Li $^{1}$ \\ ${ }^{1}$ School of Basic Medical Sciences, Tianjin Medical University, Tianjin, China \\ ${ }^{2}$ Tianjin Union Medical Center, Tianjin, China \\ ${ }^{3}$ Medical Genetic Institute of Henan Province, Henan Provincial People's Hospital, People's Hospital of Zhengzhou University, \\ Zhengzhou, Henan, China \\ ${ }^{4}$ Department of Clinical Laboratory, the Fifth Central Hospital of Tianjin, Tianjin, China \\ ${ }^{5}$ Jining Tumor Hospital, Jining No.1 People's Hospital North Campus, Shandong, China \\ ${ }^{6}$ Traditional Chinese Medical Hospital of Changle, Shandong, China \\ *These authors contributed equally to this work
}

Correspondence to: Xichuan Li, email: xichuanli@tmu.edu.cn

Keywords: solid tumors, NRF2, prognosis, meta-analysis

Received: June 10, $2017 \quad$ Accepted: July 25, $2017 \quad$ Published: August 03, 2017

Copyright: Wang et al. This is an open-access article distributed under the terms of the Creative Commons Attribution License 3.0 (CC BY 3.0), which permits unrestricted use, distribution, and reproduction in any medium, provided the original author and source are credited.

\section{ABSTRACT}

Nuclear factor E2-related factor 2 (NRF2), a transcription factor, is known as a potential therapeutic target of solid tumor for that it is a master regulator of the injury and inflammation response, including controlling antioxidant cell progress. Recent studies showed that NRF2 played significant roles in tumorigenesis and tumor progression, however no association and relationship between NRF2 expression and different clinical manifestation of solid tumor had been accurately evaluated. The present meta-analysis picked up 17 suitable articles from EMBASE, PubMed, and ISI Web of Science databases, including 2238 patients. Combined with results of hazard ratios (HRs) and $95 \%$ confidence intervals (CIs), we concluded that a higher expression of NRF2 would have worse impact on overall survival ( $\mathrm{HR}=2.29,95 \% \mathrm{CI}$ 1.80-2.91, $P<0.05$ ) and disease-free survival (HR $=2.34,95 \%$ CI $1.36-4.00, P<$ 0.05 ) by a random-effect model. Moreover, further results were positively correlated to the clinical diagnosis, curative effect observation and prognosis, including tumor differentiation, lymph node metastasis, distant metastasis and clinical stage. Consequently, our data shown that NRF2 is a potential poor prognostic factor in a variety of solid tumors.

\section{INTRODUCTION}

Oxidative stress played important roles in carcinogenesis [1]. Reactive oxygen species (ROS) damaged nucleotide, protein and lipids, which are generated by ionizing radiation [2], chronic inflammatory [3] or environmental agents $[4,5]$, then result in cell carcinogenesis. The intracellular ROS stimulated MAPK/ PAK signal pathways [6], activated the downstream transcription factor (NRF2, AP1, NF-кB, and HIF-1 $\alpha$ ) [7] and consequently initiated downstream factors to degrade ROS and improved the cell survival.
Among the oxidative stress responsive transcription factors, NRF2 aroused extensive concern for its important role in cancer. NRF2 is a basic region-leucine zipper type transcription factor, combined with Keap1 (kelch like ECH associated protein 1) in basal stress condition and degraded by ubiquitin system through Keap1 at the same time [8]. In oxidative stress condition, the specific cysteines of Keap1 was oxidized or modified by ROS, which altered the conformation of Keap1 and derestricted NRF2 to activate its downstream anti-oxidative genes [9-11].

NRF2 is a double-edged sword in carcinogenesis. On the one hand, NRF2 degraded intracellular carcinogens 
by activating downstream genes to prevent carcinogenesis [12]. On the other hand, chemotherapy drugs increased activation of NRF2, which can counteract the role of drug molecules and promote the cell survival, finally result in chemotherapy resistance. Immunohistochemical researches in non-small cell lung cancer [13] and epithelial ovarian cancer [14] demonstrated that high expression of NRF2 is relevant to platinum resistant. Additionally, NRF2 itself can increase cell survival under stressing, and gainof-function mutations of NRF2 have been found in various type of cancer, which loss its binding capacity with Keap1 but retains transcriptional activity [15]. Therefore, NRF2 is accounted by some researchers an "oncogenic" [11].

The complex roles of NRF2 in carcinogenesis remained wide interest and controversy in cancer biologists. More and more researchers have realized the "paradox" of NRF2 [7, 11, 12, 16] however, there is no comprehensive and quantitative analysis against the roles of NRF2 in carcinogenesis and cancer therapy. This meta-analysis aimed to evaluate the roles of NRF2 in carcinogenesis and prognosis from previous research data, and tried to provide a panoramic picture of NRF2 in cancer biology.

\section{RESULTS}

\section{Study selection and characteristics description}

The detailed study selection is shown as Figure 1. A total of 662 publications were identified in databases of EMBASE, PubMed, and ISI Web of Science. 645 of those were excluded, due to laboratory studies, articles (review), repetitive research, without full texts, detection method or studies irrelevant to the current analysis. 17 publications [13, 17-32], which includes 2238 patients, were included in this study. Each of the 17 eligible studies was assessed independently by two investigators according to the Newcastle-Ottawa Scale (NOS). Briefly, NOS are classified into the three dimensions of selection, comparability, and ascertainment of outcome. Each appraised study can be awarded a score ranged from 0 to 9. The score of 1-3, 4-6, 7-9 was defined as low, middle and high quality, respectively. Additionally, 11 of the studies obtained scores $\geq 7$ in methodological assessment, indicating a high quality for the majority of these studies.

The participants in the studies covered kinds of countries and cancer types. The most focuses on China $(47.06 \%)$ and Finland $(23.53 \%)$, the rest are Japan (17.65\%), America (5.89\%) and Korea (5.89\%). Main type of cancer among 2238 patients were lung cancer $(n$ $=762)$, ovarian cancer $(n=208)$, gastric cancer $(n=175)$. Moreover, the median patient age ranged from 50.0 to 60.0 years. Additionally, $>10 \%$ positive tumor cells and scores $\geq 1$ were the most appropriate cut-off values for overall survival, $>10 \%$ positive tumor cells was a more suitable cut-off value for disease-free survival simultaneously. The detailed characteristics are listed in Table 1.

\section{NRF2 and overall survival}

17 studies with data from 2238 patients were available to evaluate the effect of NRF2 expression on

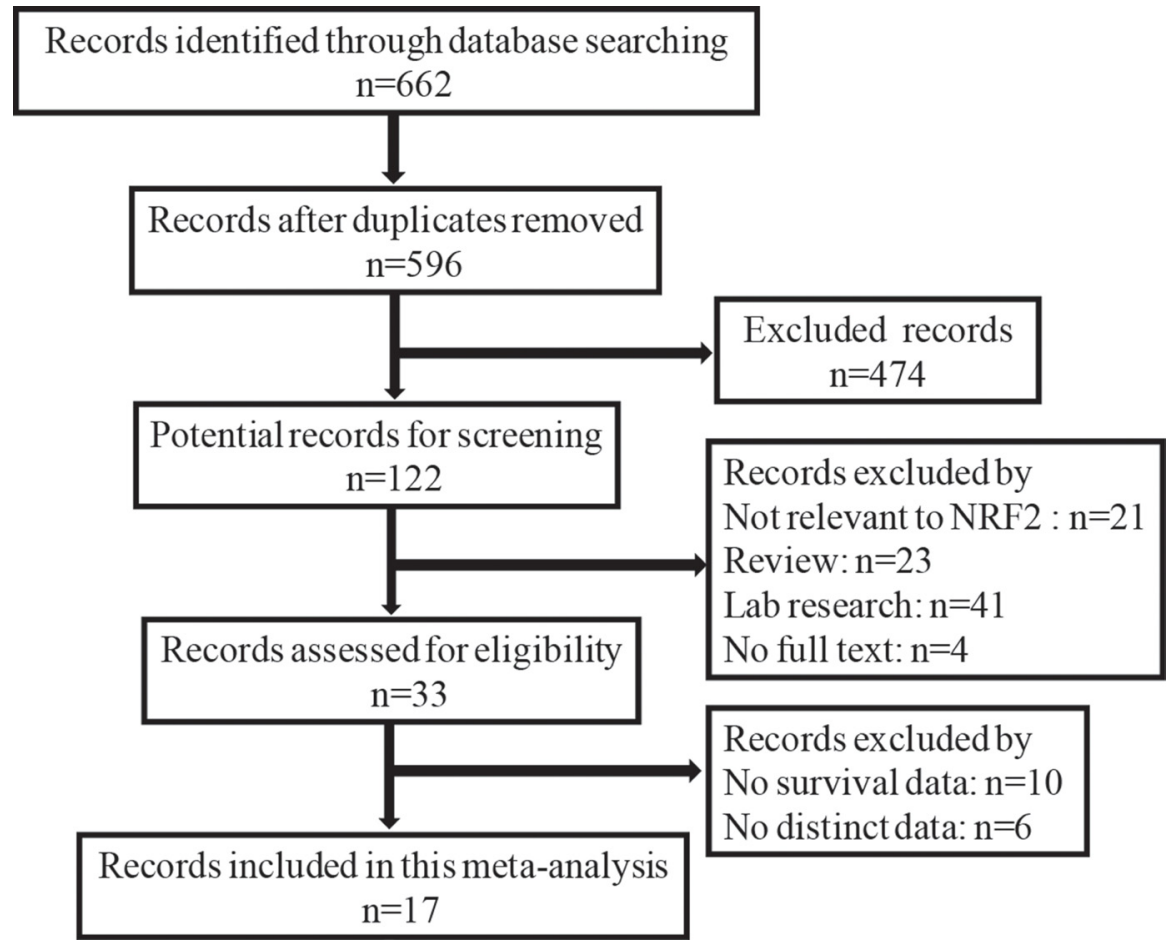

Figure 1: Flow diagram of the selection of eligible studies. 
OS. The pooled HR revealed that over-expressed NRF2 was significantly associated with poor OS in multivariate analysis (HR: 2.29, 95\% CI: 1.80-2.91, $P<0.05$, Figure 2). Low significant heterogeneity $\left(\mathrm{I}^{2}=38.8 \%\right)$ was observed when using a random-effects model to analyze the pooled HR of the OSs. This reveals excessive NRF2 expression had a poor prognosis in cancer patients (Figure 2).

\section{NRF2 and disease-free survival}

Only 5 articles reported the relevance between the NRF2 expression and DFS, the pooled HR was 2.34 (95\% CI: $1.36-4.00, P<0.05)$ with high heterogeneity $\left(\mathrm{I}^{2}=65.3 \%\right)$ by a random-effects model. The results in Figure 3 indicated that the high expression of NRF2 is worse than the control group (Figure 3).

\section{NRF2 and slinicopathological parameters}

The clinical and pathological parameters collected from the eligible studies were presented in Table 2. Meanwhile, pooled results of the correlations were identified between the high expression of NRF2 and clinicopathological features of patients with solid tumors. We found that the over-expressed NRF2 was positively associated with tumor differentiation $(\mathrm{OR}=2.72,95 \%$ CI: 1.30-5.70), lymph node metastasis (OR $=2.07$, 95\% CI: $1.13-3.78)$, distant metastasis $(\mathrm{OR}=8.21,95 \%$
CI: $1.57-43.00)$ and clinical stage $(\mathrm{OR}=3.37,95 \% \mathrm{CI}$ : 1.98-5.73) with statistical significance according to the multivariate analysis. However, NRF2 was not relevant to other clinicopathological features such as the gender (OR $=1.28,95 \% \mathrm{CI}: 0.73-2.24)$ and tumor size status $(\mathrm{OR}=$ 2.11, 95\% CI: 0.88-5.03) (Table 3).

\section{Assessment of heterogeneity and sensitivity}

There was low heterogeneity $\left(\mathrm{I}^{2}>30 \%\right)$ between studies in OS analyses. So the random-effect model was therefore adopted in these studies. By successively omitting each study from the aggregated survival metaanalyses, a sensitivity analysis was performed to evaluate the influence of each individual study on the pooled HR (Figure 4). The results revealed that the pooled estimates of the effect of over-expressed NRF2 on the OS of patients with solid tumors did not vary substantially with the exclusion of any individual study, which implies that the results of this meta-analysis are stable.

\section{Publication bias}

We constructed Begg's funnel plot with pseudo 95\% confidence limits tests to evaluate the publication bias risk in these applicable studies. The shapes of the funnel plots for OS, DFS and clinicopathological features of patients were almost symmetrical, indicated that there is no

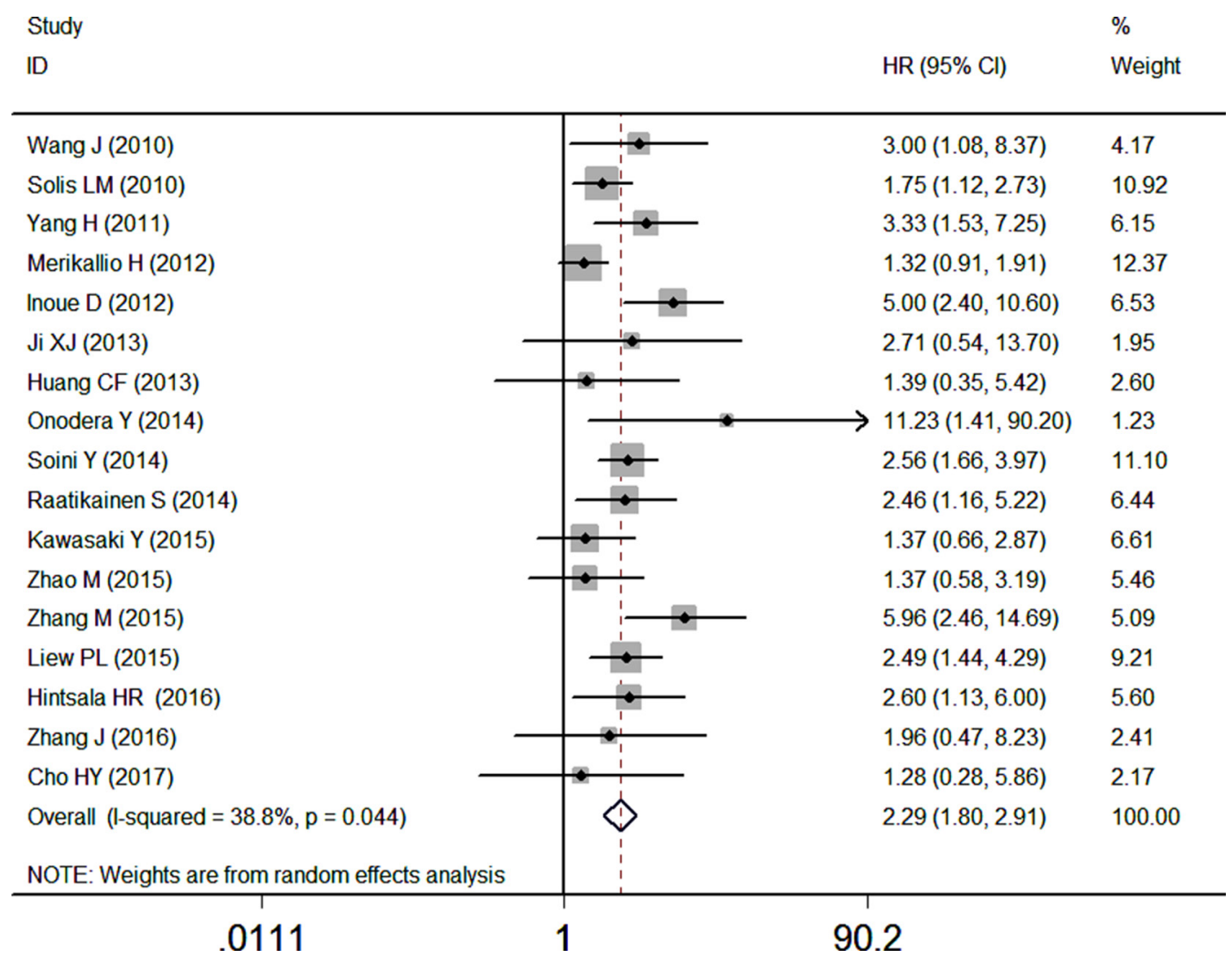

Figure 2: Forest plot describing the association between over-expressed NRF2 and OS. 
Table 1: Main characteristics of studies exploring the relationship between Nrf2 expression and tumor prognosis

\begin{tabular}{|c|c|c|c|c|c|c|c|c|c|c|c|}
\hline Author & Year & Region & Cancer Type & $\begin{array}{l}\text { Stage / } \\
\text { Grade }\end{array}$ & $\begin{array}{c}\text { No. of } \\
\text { Patients }\end{array}$ & $\begin{array}{c}\text { Age Median } \\
\text { (Range) }\end{array}$ & $\begin{array}{l}\text { Follow-up Time } \\
\text { Median (range) }\end{array}$ & Detection Method & Cut-off & Outcomes & NOS Score \\
\hline Onodera Y [17] & 2014 & Japan & BRCA & I-III & 106 & $57(31-81)$ & $103 \mathrm{~m}(3-175)$ & IHC(sc-13032X) & $\geq 10 \%$ & OS,DFS & 7 \\
\hline Wang J [18] & 2010 & China & GBC & $\mathrm{I}-\mathrm{V}$ & 59 & 60 & $28.7 \mathrm{~m}( \pm 14.4)$ & $\mathrm{IHC}(\mathrm{sc}-722)$ & $\geq 25 \%$ & OS & 6 \\
\hline Kawasaki Y [19] & 2015 & Japan & $\mathrm{GC}$ & I-III & 175 & $66(31-84)$ & NR & IHC(sc-365949) & $\geq 100 \%$ & OS & 8 \\
\hline Zhao M [20] & 2015 & China & Gliomas & I-IV & 75 & 50 & $5 \mathrm{y}$ & IHC(Abcam) & $>10 \%$ & OS, DFS & 6 \\
\hline Ji XJ [21] & 2013 & China & Glioblastoma & $0-3$ & 49 & $52(27-82)$ & $3 y$ & IHC(Abcam) & scores $>5$ & OS, PFS & 5 \\
\hline Zhang M [22] & 2015 & China & $\mathrm{HCC}$ & $0-3$ & 80 & 60 & $16.6 \mathrm{~m}$ & IHC( Santa Cruz) & scores $>2$ & OS, DFS & 6 \\
\hline Merikallio H [23] & 2012 & Finland & $\mathrm{LC}$ & NR & 289 & NR & NR & IHC( Santa Cruz) & $\geq 5 \%$ & os & 8 \\
\hline Yang H [24] & 2011 & China & NSCLC & IIIB or IV & 60 & NR & NR & IHC(Beijing Bio) & $\geq 50 \%$ & OS, PFS & 6 \\
\hline Solis LM [13] & 2010 & USA & NSCLC & I-IV & 304 & 66 & $5 \mathrm{y}$ & IHC( Santa Cruz) & score $>0$ & OS, RFS & 8 \\
\hline Inoue D [25] & 2012 & Japan & NSCLC & I-III & 109 & $65.6(23-82)$ & $1626 \mathrm{~d}(17-3366)$ & IHC(sc-13032X) & $\geq 10 \%$ & OS & 7 \\
\hline Hintsala HR [26] & 2016 & Finland & Melanoma & $\mathrm{I}-\mathrm{V}$ & 121 & 70 & NR & IHC(Santa Cruz) & NR & OS & 7 \\
\hline Huang CF [29] & 2013 & China & OSCC & NR & 43 & NR & $24 \mathrm{~m}(12-43)$ & IHC(Burlingame) & NR & OS, DFS & 5 \\
\hline Zhang J [30] & 2016 & China & Osteosarcoma & NR & 102 & 14 & NR & IHC(Santa Cruz) & scores $\geq 3$ & OS & 7 \\
\hline Liew PL [28] & 2015 & China & $\mathrm{OC}$ & I-IV & 108 & 50 & NR & IHC(NR) & $\geq 50 \%$ & OS, DFS & 7 \\
\hline Soini Y [31] & 2014 & Finland & $\mathrm{PC}$ & I-IV & 103 & NR & NR & IHC(Santa Cruz) & $\geq 5 \%$ & OS & 7 \\
\hline Raatikainen S [32] & 2014 & Finland & Prostate & NR & 240 & 63 & $11.7 \mathrm{~m}(3.3-25.8)$ & IHC(Santa Cruz) & $\geq 50 \%$ & OS, DFS & 8 \\
\hline Cho HY [27] & 2017 & Korea & $\mathrm{OC}$ & $1-3$ & 100 & 55 & $55.3 \mathrm{~m}$ & IHC(Santa Cruz) & scores $\geq 1$ & OS, DFS & 7 \\
\hline
\end{tabular}

GC: Gastric Cancers; CRC: Colorectal Cancers; NPC: Nasopharyngeal Carcinoma; NSCLC: Non-Small Cell Lung Cancers; OC: Ovarian Cancers; OSCC: Oral Squamous Cell Carcinoma; HCC: Hepatocellular Carcinoma; SSCC: Sinonasal Squamous Cell Carcinoma; BRCA: Breast Cancer; GBC: Gallbladder Cancer ; Pancreatic adenocarcinoma: PC; lung cancer : LC; NR: Not Reported; y: year; m: month; d: day;

OS: Overall Survival; DFS: Disease-Free Survival.

statistically significant difference, therefore no significant publication bias (Figure 5). Thus, in these incorporated papers, it was found that there was no evidence of significant publication bias after assessing and the results of this meta-analysis are reliable.

\section{DISCUSSION}

Our meta-analysis demonstrated that the excessive expression of NRF2 was related to poor OS $(\mathrm{HR}=2.29$,
95\% CI: $1.80-2.91, P<0.05)$ and DFS $(\mathrm{HR}=2.34,95 \%$ CI 1.36-4.00, $P<0.05)$ in various type of cancer patients. Also, the association between NRF2 expression and different clinicopathological parameters was consistent, which indicated general roles of NRF2 in cancer prognosis. NRF2-Keap1 pathway played essential roles in the response of oxidative stress, but exhibited "doubleedged" effect in carcinogenesis. This meta-analysis help us to re-understand and re-discovery the roles of NRF2 in tumorigenesis, and figured out the relevance between

Study
ID
Onodera Y (2014)
Raatikainen S (2014)
Liew PL (2015)
Cho HY (2017)

Figure 3: Forest plot describing the association between over-expressed NRF2 and DFS. 
Table 2: Summarized data of clinical and pathological parameters from the eligible studies

\begin{tabular}{|c|c|c|c|c|c|c|c|c|c|c|c|c|c|c|c|c|c|c|c|c|c|c|c|c|}
\hline \multirow{3}{*}{$\begin{array}{l}\begin{array}{l}\text { First } \\
\text { author }\end{array} \\
\\
\quad \text { Nrf2 }\end{array}$} & \multicolumn{4}{|c|}{ Gender } & \multicolumn{4}{|c|}{ Tumor differentiation } & \multicolumn{4}{|c|}{ Tumor size } & \multicolumn{4}{|c|}{ Lymph node metastasis } & \multicolumn{4}{|c|}{ Distant metastasis } & \multicolumn{4}{|c|}{ Clinical stage } \\
\hline & \multicolumn{2}{|c|}{ Male } & \multicolumn{2}{|c|}{ Female } & \multicolumn{2}{|c|}{$\begin{array}{l}\text { Poor+Moderate/ } \\
\text { undifferentiated }\end{array}$} & \multicolumn{2}{|c|}{$\begin{array}{c}\text { Well/ } \\
\text { differentiated }\end{array}$} & \multicolumn{2}{|c|}{ T3-4 } & \multicolumn{2}{|c|}{ T1-2 } & \multicolumn{2}{|c|}{ Yes } & \multicolumn{2}{|c|}{ No } & \multicolumn{2}{|c|}{ Yes } & \multicolumn{2}{|c|}{ No } & \multicolumn{2}{|c|}{ III-IV } & \multicolumn{2}{|c|}{ I-II } \\
\hline & + & - & + & - & + & - & + & - & + & - & + & - & + & - & + & - & + & - & + & - & + & - & + & - \\
\hline $\begin{array}{l}\text { Onodera Y } \\
\text { [17] }\end{array}$ & NA & NA & $\mathrm{NA}$ & $\mathrm{NA}$ & 42 & 44 & 5 & 15 & & 29 & 16 & 30 & 27 & 24 & 20 & 35 & $\mathrm{NA}$ & NA & NA & NA & 14 & 10 & 33 & 49 \\
\hline $\begin{array}{l}\text { Wang J } \\
{[18]}\end{array}$ & 13 & 5 & 32 & 9 & 44 & 10 & 1 & 4 & $\mathrm{NA}$ & NA & $\mathrm{NA}$ & NA & 27 & 0 & 18 & 14 & 18 & 0 & 27 & 14 & 21 & 6 & 6 & 8 \\
\hline $\begin{array}{l}\text { Kawasaki Y } \\
{[19]}\end{array}$ & 65 & 51 & 43 & 16 & 74 & 30 & 34 & 37 & 89 & 36 & 19 & 31 & 74 & 35 & 34 & 32 & $\mathrm{NA}$ & NA & NA & NA & 68 & 27 & 40 & 40 \\
\hline $\begin{array}{l}\text { Zhao M } \\
{[20]}\end{array}$ & 30 & 15 & 16 & 14 & NA & $\mathrm{NA}$ & NA & NA & $\mathrm{NA}$ & NA & NA & NA & NA & NA & NA & NA & NA & $\mathrm{NA}$ & NA & NA & 30 & 6 & 16 & 23 \\
\hline $\begin{array}{l}\text { Zhang M } \\
{[22]}\end{array}$ & 34 & 10 & 14 & 7 & 28 & 2 & 20 & 15 & 27 & 4 & 21 & 13 & $\mathrm{NA}$ & NA & NA & NA & 29 & 1 & 19 & 16 & NA & NA & NA & NA \\
\hline $\begin{array}{l}\text { Yang } \mathrm{H} \\
\text { [24] }\end{array}$ & 26 & 14 & 8 & 12 & 17 & 9 & 8 & 8 & $\mathrm{NA}$ & NA & NA & NA & NA & NA & NA & NA & NA & NA & NA & NA & 28 & 14 & 6 & 12 \\
\hline $\begin{array}{l}\text { Inoue D } \\
{[25]}\end{array}$ & 31 & 47 & 6 & 25 & 10 & 23 & 27 & 49 & 21 & 48 & 16 & 24 & 14 & 21 & 23 & 51 & $\mathrm{NA}$ & NA & NA & NA & NA & NA & NA & $\mathrm{NA}$ \\
\hline $\begin{array}{l}\text { Zhang J } \\
\text { [30] }\end{array}$ & 37 & 11 & 42 & 12 & NA & $\mathrm{NA}$ & NA & $\mathrm{NA}$ & $\mathrm{NA}$ & NA & NA & NA & NA & NA & NA & NA & 40 & 9 & 32 & 21 & NA & $\mathrm{NA}$ & NA & NA \\
\hline
\end{tabular}

NRF2 expression and patients' survival. The present metaanalysis exhibited no publication bias for OS according to the funnel plot and Begg's test. Thus, the results in our study has a high degree of credibility.

Given the difference of tumor types and population, the sensitivity of OS in most articles reflected the relevance between NRF2 level and carcinogenesis is stable, and the prognosis value of NRF2 is universal. Nevertheless, there are several limitations on this article worthy of our attention. A potential limitation is the high heterogeneity across diverse publications for DFS and different clinicopathological parameters. The number of samples was small, which is not sufficient to detect a remarkably difference between them.

Another limitation of our meta-analysis is lack of stratified analysis for different tumor subtype. Although there are many studies on NRF2 in various type of cancer, little of them focused on subtype of specific cancer. For breast cancer, though, the sub-classification of breast cancer was also classified according to ERpositive and negative [17], the lack of ductal carcinoma, adenocarcinoma such morphological classification of discussion, and this degree of malignancy for breast cancer and NRF2 correlation also has important reference

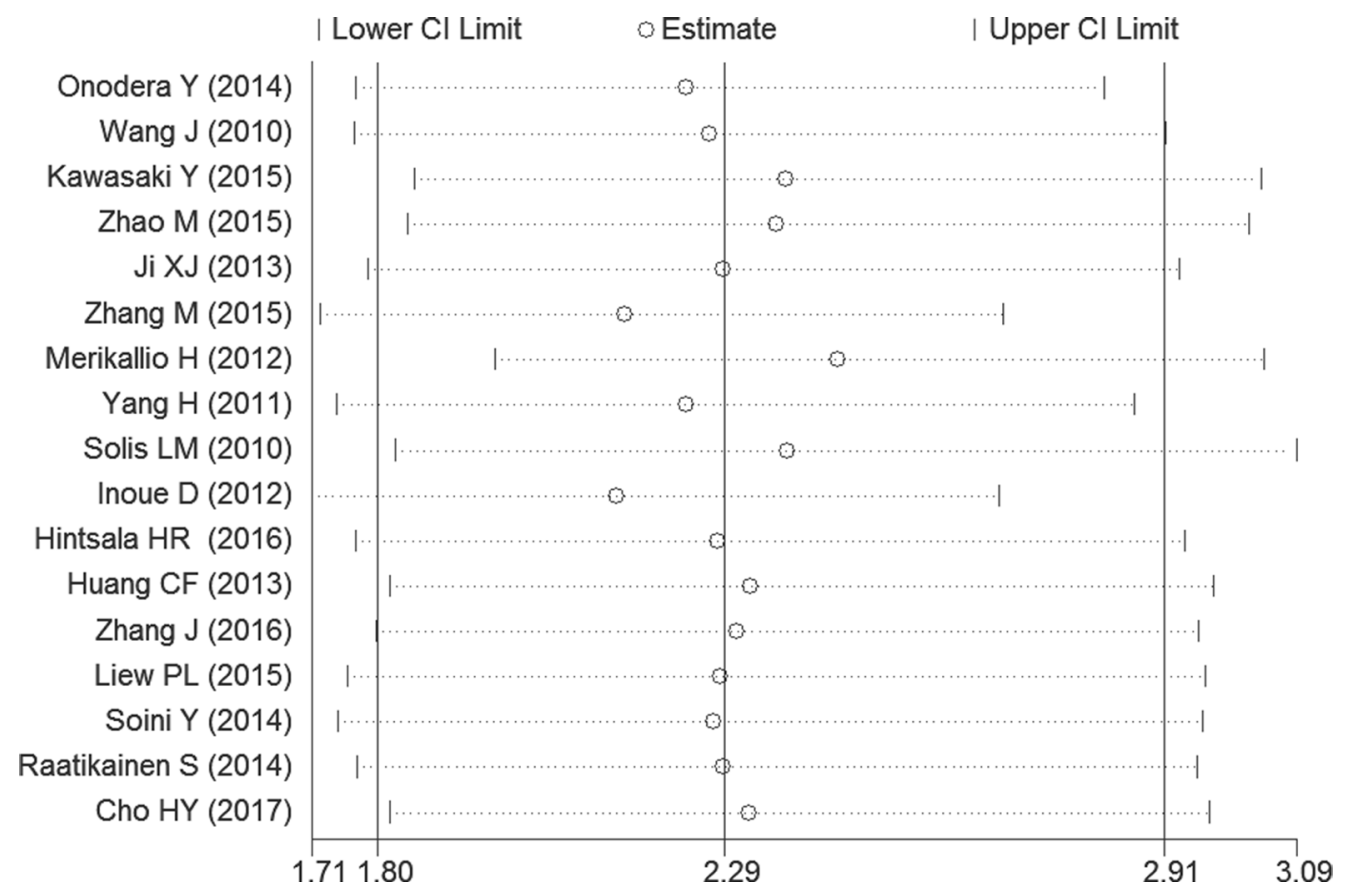

Figure 4: Sensitivity analysis of the OS in the meta-analysis. 
Table 3: Meta-analysis results of the associations of increased Nrf2 expression with clinicopathological parameters

\begin{tabular}{|c|c|c|c|c|}
\hline Clinicopathological parameter & Ref & Overall OR (95\%CI) & $P$-value & Heterogeneity test ( $I^{2}, P$-value $)$ \\
\hline Gender (male vs female) & {$[18-20],[22],[24,25],[30]$} & $1.28(0.73-2.24)$ & 0.392 & $(56.2 \%, 0.033)$ \\
\hline Differentiation (poor VS well) & {$[17-20],[24,25]$} & $2.72(1.30-5.70)$ & 0.008 & $(60.8 \%, 0.026)$ \\
\hline Tumor size (T3-4 vs T1-2) & [17], [19], [22], [25] & $2.11(0.88-5.03)$ & 0.094 & $(75.9 \%, 0.006)$ \\
\hline Lymph node metastasis (yes vs no) & {$[17-19],[25]$} & $2.07(1.13-3.78)$ & 0.018 & $(42.6 \%, 0.156)$ \\
\hline Distant metastasis (yes vs no) & {$[18],[22],[30]$} & $8.21(1.57-43.00)$ & 0.013 & $(57.8 \%, 0.094)$ \\
\hline Clinical stage (III-IV vs I-II) & {$[17-20],[24]$} & $3.37(1.98-5.73)$ & 0.000 & $(24.2 \%, 0.260)$ \\
\hline
\end{tabular}

value. For lung cancer, the study of NRF2 mainly focused on non-small cell lung cancer [13,24], but less focused on small cell lung cancer subtypes $[23,25]$. For other cancers, many of them have no stratified analysis for different tumor subtype.

A possible mechanism for the poor prognosis with excessive NRF2 expression can be inferred from the existing studies of NRF2: First, NRF2 promotes tumorgenicity itself. A research in 2011 indicate that oncogenes like KRAS, MYC and BRAF can promote the expression of NRF2 to degrade ROS to make a more reduced intercellular environment, therefore, protects cancer cell from oxidative stress and promote cell proliferation and tumorigenecity [33]. Second, NRF2 mediated various chemotherapy drugs resistance, which is reported by the researches in lung cancer [13] and ovarian cancer [14] by studying in cell lines and animal models [34-36].

For the "paradox" of NRF2' role in tumorigenesis, some researchers thought that NRF2 may act diversely roles in different expression level [12] and different stage of tumorigenesis [16]: It can prevent tumorigenesis in premalignant cell or early stage malignant cell, but promote tumorigenesis and chemotherapy resistance
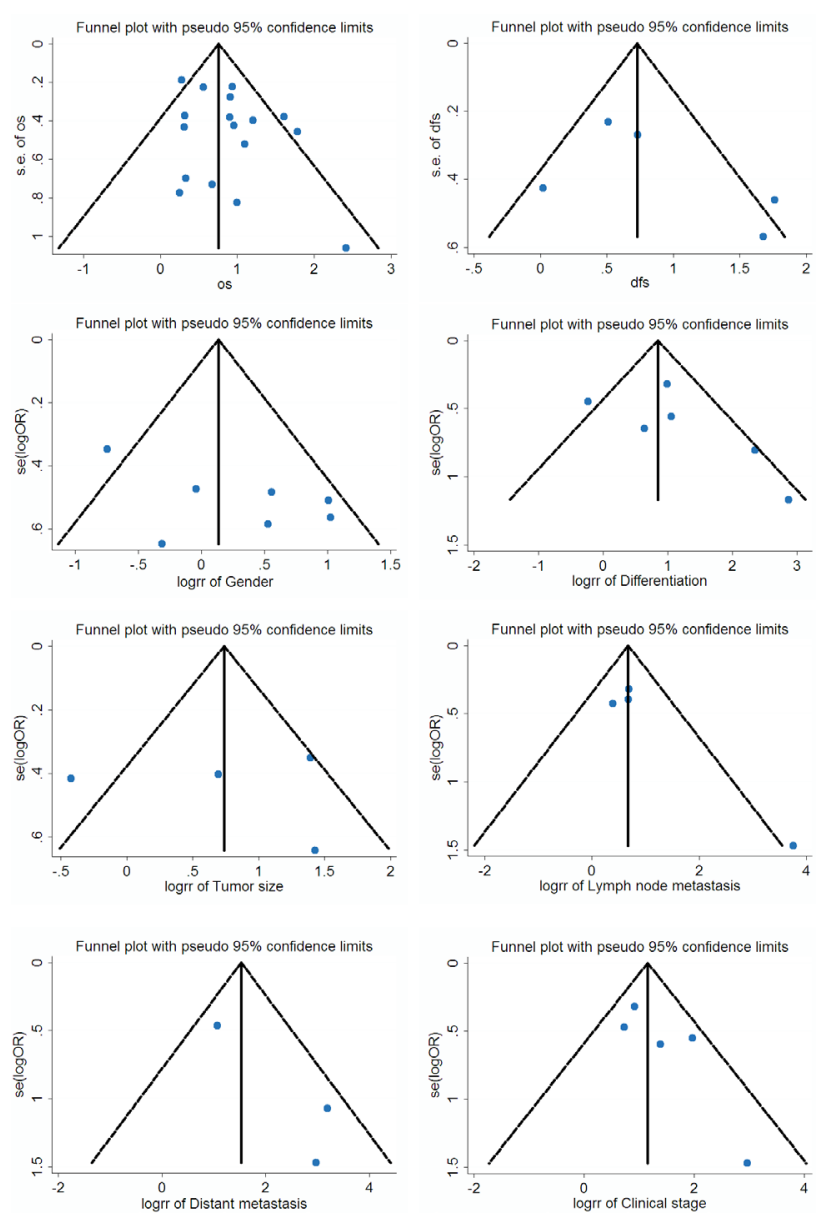

Figure 5: Funnel plot for the assessment of potential publication bias regarding OS, DFS and clinicopathological features of patients in the meta-analysis. 
in malignant cell, which is like the role of TGF- $\beta$ in tumorigenesis [37]. Further stratified analysis of the roles of NRF2 in different stage of cancer patients can be performed to verify this hypothesis in the future. Furthermore, quantitative biological technique can be also utilized to quantify the level of NRF2 in the whole process of tumorigenesis to give more instructive advice for the prognosis of different stage of cancer. Whether meta-analysis can be used for different periods of cancer patients with their survival and NRF2 expression level analysis, to verify or deny this view? Such analysis will arouse the interest of the majority of researchers.

\section{MATERIALS AND METHODS}

\section{Search strategy and selection criteria}

We systematically select the appropriate articles from the EMBASE, PubMed, and ISI Web of science databases using the following keywords in all possible combinations: "NRF2/Nuclear factor E2-related factor 2, cancer/tumor, prognosis/prognostic/ survival". As of March 31, 2017, all publications on NRF2 are eligible for inclusion except for the following: (1) reviews, letters, editorials, and expert opinion, case reports; (2) overlapping articles or irrelevant article; (3) articles that cannot be extracted the original data; and (4) insufficient data for estimating the odds ratio (OR) or hazard ratio (HR) and 95\% confidence interval (CI) [38]. The articles we selected are subject to the following conditions: (1) the expression of NRF2 is detected by immunohistochemistry in patients; (2) associations of NRF2 expression with overall survival (OS) or disease-free survival (DFS); (3) pathological diagnosis of different tumor types or clinicopathological features were described; and (4) When the same author reports the same crowd, the most complete result is hired.

\section{Data extraction}

Two investigators (Chunze Zhang and Litao Qin) independently used a standardized data-extract form, and collecting information as follows: first author's name, publication date, the patient's region, type of cancer, number of patients, NRF2 detection method, antibody source, number of patients with NRF2-positive, followup times, cut-off values, and survival data (Table 1). Any disagreements were adjudicated by discussion until a consensus was reached [39].

\section{Statistical method of meta-analyses}

This meta-analysis was performed using Stata 12.0 (Stata Corporation, College 216 Station, TX, USA) software. The results of multivariate analysis were based on the Cox proportional hazard model. Pooled estimates of HRs and their 95\% CIs were used to estimate the association between NRF2 expression and patients' survival. The chisquared test (Cochrane' $\mathrm{s}$ $Q$ test) and I-squared statistical test were used to analyze the heterogeneity between studies. When the result of a $Q$-test $\left(I^{2}>30 \%\right.$ or $\left.P<0.05\right)$ indicated heterogeneity, the random-effects model was used for the meta-analysis [40]. HR with its value over 1.0 indicated poor prognosis patients with increased NRF2 expression. Beyond that, we estimated data by sampling variation for the calculation of ORs and 95\% confidence interval (CI) [41], which was used to evaluate the correlation between NRF2 expression and the risk of clinical patients' diagnosis, such as clinical stage, lymph node metastasis and distant metastasis. Moreover, Begg's funnel plot aimed to examine the potential risk of publication bias $[42,43]$. $P \leq 0.05$ was considered to be statistically significant in this analysis.

\section{Author contributions}

Lingling Wang conceived and carried out the analysis. Chunze Zhang, Litao Qin and Jingyue Xu performed literature search, study selection, data extraction and quality assessment. Xiaobo Li and Wenhong Wang conducted statistical analysis, Lingqin Kong and Taizhen Zhou prepared tables and figures. Xichuan Li wrote the manuscript. All authors reviewed the manuscript.

\section{CONFLICTS OF INTEREST}

The authors declare no potential conflicts of interest.

\section{FUNDING}

This work was supported by grants 81472681 to X.L. from the National Natural Science Foundation of China, and grant 2014KR14 to C.Z. from the Foundation of Tianjin Health Bureau.

\section{REFERENCES}

1. Klaunig JE, Xu Y, Isenberg JS, Bachowski S, Kolaja KL, Jiang J, Stevenson DE, Walborg EF Jr. The role of oxidative stress in chemical carcinogenesis. Environ Health Perspect. 1998; 106:289-95. https://doi.org/10.1289/ehp.98106s1289.

2. Tulard A, Hoffschir F, de Boisferon FH, Luccioni C, Bravard A. Persistent oxidative stress after ionizing radiation is involved in inherited radiosensitivity. Free Radic Biol Med. 2003; 35:68-77. https://doi.org/10.1016/ S0891-5849(03)00243-0.

3. Babior BM. NADPH oxidase: an update. Blood. 1999; 93:1464-76.

4. Jiang J, Xu Y, Klaunig JE. Induction of oxidative stress in rat brain by acrylonitrile (ACN). Toxicol Sci. 1998; 46:33341. https://doi.org/10.1093/toxsci/46.2.333. 
5. Siesky AM, Kamendulis LM, Klaunig JE. Hepatic effects of 2-butoxyethanol in rodents. Toxicol Sci. 2002; 70:252-60. https://doi.org/10.1093/toxsci/70.2.252.

6. Wu WS. The signaling mechanism of ROS in tumor progression. Cancer Metastasis Rev. 2006; 25:695-705. https://doi.org/10.1007/s10555-006-9037-8.

7. Klaunig JE, Kamendulis LM, Hocevar BA. Oxidative stress and oxidative damage in carcinogenesis. Toxicol Pathol. 2010; 38:96-109. https://doi. org/10.1177/0192623309356453.

8. Cullinan SB, Gordan JD, Jin J, Harper JW, Diehl JA. The Keap1-BTB protein is an adaptor that bridges Nrf2 to a Cul3-based E3 ligase: oxidative stress sensing by a Cul3Keap1 ligase. Mol Cell Biol. 2004; 24:8477-86. https://doi. org/10.1128/MCB.24.19.8477-8486.2004.

9. Itoh K, Wakabayashi N, Katoh Y, Ishii T, Igarashi K, Engel JD, Yamamoto M. Keap1 represses nuclear activation of antioxidant responsive elements by Nrf2 through binding to the amino-terminal Neh2 domain. Genes Dev. 1999; 13:76-86. https://doi.org/10.1101/gad.13.1.76.

10. Wakabayashi N, Dinkova-Kostova AT, Holtzclaw WD, Kang MI, Kobayashi A, Yamamoto M, Kensler TW, Talalay P. Protection against electrophile and oxidant stress by induction of the phase 2 response: fate of cysteines of the Keap1 sensor modified by inducers. Proc Natl Acad Sci USA. 2004; 101:2040-45. https://doi.org/10.1073/pnas.0307301101.

11. Taguchi K, Motohashi H, Yamamoto M. Molecular mechanisms of the Keap1-Nrf2 pathway in stress response and cancer evolution. Genes Cells. 2011; 16:123-40. https:// doi.org/10.1111/j.1365-2443.2010.01473.x.

12. Kensler TW, Wakabayashi N. Nrf2: friend or foe for chemoprevention? Carcinogenesis. 2010; 31:90-99. https:// doi.org/10.1093/carcin/bgp231.

13. Solis LM, Behrens C, Dong W, Suraokar M, Ozburn NC, Moran CA, Corvalan AH, Biswal S, Swisher SG, Bekele BN, Minna JD, Stewart DJ, Wistuba II. Nrf2 and Keap1 abnormalities in non-small cell lung carcinoma and association with clinicopathologic features. Clin Cancer Res. 2010; 16:3743-53. https://doi.org/10.1158/1078-0432. CCR-09-3352.

14. Konstantinopoulos PA, Spentzos D, Fountzilas E, Francoeur N, Sanisetty S, Grammatikos AP, Hecht JL, Cannistra SA. Keap1 mutations and Nrf2 pathway activation in epithelial ovarian cancer. Cancer Res. 2011; 71:5081-89. https://doi. org/10.1158/0008-5472.CAN-10-4668.

15. Kim YR, Oh JE, Kim MS, Kang MR, Park SW, Han JY, Eom HS, Yoo NJ, Lee SH. Oncogenic NRF2 mutations in squamous cell carcinomas of oesophagus and skin. J Pathol. 2010; 220:446-51. https://doi.org/10.1002/path.2653.

16. Sporn MB, Liby KT. NRF2 and cancer: the good, the bad and the importance of context. Nat Rev Cancer. 2012; 12:564-71. https://doi.org/10.1038/nrc3278.

17. Onodera Y, Motohashi H, Takagi K, Miki Y, Shibahara Y, Watanabe M, Ishida T, Hirakawa H, Sasano H, Yamamoto
M, Suzuki T. NRF2 immunolocalization in human breast cancer patients as a prognostic factor. Endocr Relat Cancer. 2014; 21:241-52. https://doi.org/10.1530/ERC-13-0234.

18. Wang J, Zhang M, Zhang L, Cai H, Zhou S, Zhang J, Wang Y. Correlation of Nrf2, HO-1, and MRP3 in gallbladder cancer and their relationships to clinicopathologic features and survival. J Surg Res. 2010; 164:e99-105. https://doi. org/10.1016/j.jss.2010.05.058.

19. Kawasaki Y, Ishigami S, Arigami T, Uenosono Y, Yanagita S, Uchikado Y, Kita Y, Nishizono Y, Okumura H, Nakajo A, Kijima Y, Maemura K, Natsugoe S. Clinicopathological significance of nuclear factor (erythroid-2)-related factor 2 (Nrf2) expression in gastric cancer. BMC Cancer. 2015; 15:5. https://doi.org/10.1186/s12885-015-1008-4.

20. Zhao $\mathrm{M}, \mathrm{Xu} \mathrm{H}$, Zhang B, Hong B, Yan W, Zhang J. Impact of nuclear factor erythroid-derived 2-like 2 and p62/sequestosome expression on prognosis of patients with gliomas. Hum Pathol. 2015; 46:843-49. https://doi. org/10.1016/j.humpath.2015.02.009.

21. Ji XJ, Chen SH, Zhu L, Pan H, Zhou Y, Li W, You WC, Gao $\mathrm{CC}$, Zhu JH, Jiang K, Wang HD. Knockdown of NF-E2-related factor 2 inhibits the proliferation and growth of U251MG human glioma cells in a mouse xenograft model. Oncol Rep. 2013; 30:157-64. https://doi.org/10.3892/or.2013.2476.

22. Zhang M, Zhang C, Zhang L, Yang Q, Zhou S, Wen Q, Wang J. Nrf2 is a potential prognostic marker and promotes proliferation and invasion in human hepatocellular carcinoma. BMC Cancer. 2015; 15:531. https://doi. org/10.1186/s12885-015-1541-1.

23. Merikallio H, Pääkkö P, Kinnula VL, Harju T, Soini Y. Nuclear factor erythroid-derived 2-like 2 (Nrf2) and DJ1 are prognostic factors in lung cancer. Hum Pathol. 2012; 43:577-84. https://doi.org/10.1016/j.humpath.2011.05.024.

24. Yang H, Wang W, Zhang Y, Zhao J, Lin E, Gao J, He J. The role of NF-E2-related factor 2 in predicting chemoresistance and prognosis in advanced non-small-cell lung cancer. Clin Lung Cancer. 2011; 12:166-71. https://doi.org/10.1016/j. cllc.2011.03.012.

25. Inoue D, Suzuki T, Mitsuishi Y, Miki Y, Suzuki S, Sugawara S, Watanabe M, Sakurada A, Endo C, Uruno A, Sasano H, Nakagawa T, Satoh K, et al. Accumulation of p62/SQSTM1 is associated with poor prognosis in patients with lung adenocarcinoma. Cancer Sci. 2012; 103:760-66. https:// doi.org/10.1111/j.1349-7006.2012.02216.x.

26. Hintsala HR, Jokinen E, Haapasaari KM, Moza M, Ristimäki A, Soini Y, Koivunen J, Karihtala P. Nrf2/ Keap1 Pathway and Expression of Oxidative Stress Lesions 8-hydroxy-2'-deoxyguanosine and Nitrotyrosine in Melanoma. Anticancer Res. 2016; 36:1497-506.

27. Cho HY, Kim K, Kim YB, Kim H, No JH. Expression Patterns of Nrf2 and Keap1 in Ovarian Cancer Cells and their Prognostic Role in Disease Recurrence and Patient Survival. Int J Gynecol Cancer. 2017; 27:412-19. https:// doi.org/10.1097/IGC.0000000000000908. 
28. Liew PL, Hsu CS, Liu WM, Lee YC, Lee YC, Chen CL. Prognostic and predictive values of Nrf2, Keap1, p16 and E-cadherin expression in ovarian epithelial carcinoma. Int J Clin Exp Pathol. 2015; 8:5642-49.

29. Huang CF, Zhang L, Ma SR, Zhao ZL, Wang WM, He KF, Zhao YF, Zhang WF, Liu B, Sun ZJ. Clinical significance of Keap1 and Nrf2 in oral squamous cell carcinoma. PLoS One. 2013; 8:e83479. https://doi.org/10.1371/journal. pone.0083479.

30. Zhang J, Wang X, Wu W, Dang H, Wang B. Expression of the Nrf2 and Keap1 proteins and their clinical significance in osteosarcoma. Biochem Biophys Res Commun. 2016; 473:42-46. https://doi.org/10.1016/j.bbrc.2016.03.047.

31. Soini Y, Eskelinen M, Juvonen P, Kärjä V, Haapasaari KM, Saarela A, Karihtala P. Nuclear Nrf2 expression is related to a poor survival in pancreatic adenocarcinoma. Pathol Res Pract. 2014; 210:35-39. https://doi.org/10.1016/j. prp.2013.10.001.

32. Raatikainen S, Aaltomaa S, Kärjä V, Soini Y. Increased nuclear factor erythroid 2-related factor 2 expression predicts worse prognosis of prostate cancer patients treated with radical prostatectomy. Hum Pathol. 2014; 45:2211-17. https://doi.org/10.1016/j.humpath.2014.07.010.

33. DeNicola GM, Karreth FA, Humpton TJ, Gopinathan A, Wei C, Frese K, Mangal D, Yu KH, Yeo CJ, Calhoun ES, Scrimieri F, Winter JM, Hruban RH, et al. Oncogeneinduced Nrf2 transcription promotes ROS detoxification and tumorigenesis. Nature. 2011; 475:106-09. https://doi. org/10.1038/nature10189.

34. Shibata T, Kokubu A, Gotoh M, Ojima H, Ohta T, Yamamoto M, Hirohashi S. Genetic alteration of Keap1 confers constitutive Nrf2 activation and resistance to chemotherapy in gallbladder cancer. Gastroenterology. 2008; 135:1358-68, 1368.e1-4. https://doi.org/10.1053/j. gastro.2008.06.082.

35. Homma S, Ishii Y, Morishima Y, Yamadori T, Matsuno Y, Haraguchi N, Kikuchi N, Satoh H, Sakamoto T, Hizawa
N, Itoh K, Yamamoto M. Nrf2 enhances cell proliferation and resistance to anticancer drugs in human lung cancer. Clin Cancer Res. 2009; 15:3423-32. https:/doi. org/10.1158/1078-0432.CCR-08-2822.

36. Jiang T, Chen N, Zhao F, Wang XJ, Kong B, Zheng W, Zhang DD. High levels of Nrf2 determine chemoresistance in type II endometrial cancer. Cancer Res. 2010; 70:548696. https://doi.org/10.1158/0008-5472.CAN-10-0713.

37. Siegel PM, Massagué J. Cytostatic and apoptotic actions of TGF- $\beta$ in homeostasis and cancer. Nat Rev Cancer. 2003; 3:807-21. https://doi.org/10.1038/nrc1208.

38. He X, Chen Z, Jia M, Zhao X. Downregulated E-cadherin expression indicates worse prognosis in Asian patients with colorectal cancer: evidence from meta-analysis. PLoS One. 2013; 8:e70858. https://doi.org/10.1371/journal. pone. 0070858 .

39. Yuan P, Cao JL, Abuduwufuer A, Wang LM, Yuan XS, Lv W, Hu J. Clinical Characteristics and Prognostic Significance of TERT Promoter Mutations in Cancer: A Cohort Study and a Meta-Analysis. PLoS One. 2016; 11:e0146803. https://doi. org/10.1371/journal.pone.0146803.

40. DerSimonian R, Laird N. Meta-analysis in clinical trials. Control Clin Trials. 1986; 7:177-88. https://doi. org/10.1016/0197-2456(86)90046-2.

41. Tierney JF, Stewart LA, Ghersi D, Burdett S, Sydes MR. Practical methods for incorporating summary time-to-event data into meta-analysis. Trials. 2007; 8:16. https://doi. org/10.1186/1745-6215-8-16.

42. Egger M, Davey Smith G, Schneider M, Minder C. Bias in meta-analysis detected by a simple, graphical test. BMJ. 1997; 315:629-34. https://doi.org/10.1136/ bmj.315.7109.629.

43. Duval S, Tweedie R. Trim and fill: A simple funnel-plotbased method of testing and adjusting for publication bias in meta-analysis. Biometrics. 2000; 56:455-63. https://doi. org/10.1111/j.0006-341X.2000.00455.x. 